\title{
Response of normal and colon cancer epithelial cells to TNF-family apoptotic inducers
}

\author{
JIRINA HOFMANOVÁ, ALENA VACULOVÁ*, MARTINA HYZD'ALOVÁ* and ALOIS KOZUBÍK \\ Laboratory of Cytokinetics, Institute of Biophysics, Academy of Sciences of the \\ Czech Republic, v.v.i., Královopolská 135, CZ-612 65 Brno, Czech Republic
}

Received September 17, 2007; Accepted October 29, 2007

\begin{abstract}
We compared the response of normal (FHC) and cancer (HT-29) human colon epithelial cells to the important apoptotic inducers TNF- $\alpha$, anti-Fas antibody and TNF-related apoptosis inducing ligand (TRAIL). The two cell lines did not respond to TNF- $\alpha(15 \mathrm{ng} / \mathrm{ml})$, expressed a limited sensitivity to anti-Fas antibody $(200 \mathrm{ng} / \mathrm{ml})$ and a different response to TRAIL $(100 \mathrm{ng} / \mathrm{ml})$. We studied apoptosis with regard to the changes at the receptor level (DR, DcR and FLIP) and at the level of mitochondria (Bid protein cleavage, Apo2.7 protein expression and caspase-9 activation). Two different approaches were used to sensitize the cells to TRAILinduced apoptosis: inhibition of protein synthesis (cycloheximide, $\mathrm{CHX}$ ) and inhibition of the pro-survival MEK/ERK pathway (U0126). While the two cell lines were markedly sensitized to all three TNF family members by $\mathrm{CHX}$, a different degree of response (especially for TRAIL) was obtained when inhibition of the MEK/ERK pathway was achieved. TRAIL-induced apoptosis was significantly enhanced by U0126 co-treatment in the HT-29 cells, but not in the FHC cells. The most significant differences between the HT-29 and FHC cells co-treated with TRAIL and U0126 were demonstrated with regard to the involvement of the mitochondrial apoptotic pathway, suggesting its importance in the regulation of cell sensitivity to the TRAIL-induced apoptosis.
\end{abstract}

\section{Introduction}

The suppression of apoptosis of colon epithelial cells may cause cellular transformation and favour progression at every stage of the adenoma-carcinoma sequence (1). Cytokines of

Correspondence to: Dr Alois Kozubík, Institute of Biophysics, Academy of Sciences of the Czech Republic, CZ-612 65 Brno, Královopolská 135, Czech Republic

E-mail:kozubik@ibp.cz

*Contributed equally

Key words: apoptosis, TNF-related apoptosis inducing ligand, TNF- $\alpha$, anti-Fas, colon the tumour necrosis factor (TNF) family have been identified as important inducers of apoptosis, but their role in regulating epithelial cell turnover is not fully understood (2). Their effect on colon cancer cells and the associated molecular and cellular mechanisms have yet to be elucidated (3). TNF- $\alpha$, Fas ligand and TNF-related apoptosis inducing ligand (TRAIL) induce apoptosis by binding to their respective death receptors (DRs) possessing intracellular death domains which recruit certain adaptor molecules to form the deathinducing signalling complex (DISC) activating the apoptotic caspase cascade (4). Through caspase- 8 activation, subsequent downstream signals are started, either through the direct activation of effector caspases (type I cells, extrinsic pathway) or by transferring a signal to mitochondria (type II cells, intrinsic pathway) mediated by cleavage of the Bid protein (5). Changes in mitochondria are associated with the activity of pro- and anti-apoptotic proteins of the $\mathrm{Bcl}-2$ protein family and start events leading to the activation of caspase-9, effector caspases, death-substrate cleavage and finally cell death (6).

In spite of the fact that TNF- $\alpha$, anti-Fas and TRAIL can generate potent antitumour activity in vivo and in vitro $(7,8)$, many cancer cells are resistant to this type of DR-mediated killing. Moreover, the therapeutic use of the TNF- $\alpha /$ TNFR or Fas/FasL system in cancer treatment has been hampered by severe side effects. In contrast to TNF- $\alpha$ and FasL, TRAIL induces apoptosis in a wide variety of transformed cell lines, but seems to have little or no cytotoxic effect on most normal cells in vitro and in vivo. The induction of apoptosis is mediated by the interaction of TRAIL with the two death receptors DR4 and DR5, and the mechanism seems to be rather different from that of TNF- $\alpha$ or FasL (9). Due to the selective effects of TRAIL on cancer cells and its ability to induce apoptosis irrespective of p53 status, it may be a safer therapeutic alternative to the other two cytokines (10). In spite of an increase in sensitivity to TRAIL-induced apoptosis during adenoma to colon carcinoma transition being detected (11), many types of cancer cells become resistant to TRAIL (12). Some cells seem to be protected from TRAIL-induced apoptosis by their expression of decoy receptors (DcR1 and DcR2), which do not transduce apoptotic signals, as well as at the level of certain molecules involved in intracellular signalling pathways (13).

In the present study, two different approaches were used in order to sensitize the colon cells to the apoptotic effects of TNF- $\alpha$, Fas antibody (anti-Fas) and TRAIL. The cell response 
to these cytokines was compared between normal (FHC) and cancer (HT-29) colon epithelial cell lines either under the inhibition of protein synthesis (cycloheximide) or inhibition of the pro-survival MEK/ERK pathway (U0126). An investigation of differences in the sensitivity/resistance of these cells may help to find molecular mechanisms of cell resistance to TNF family apoptotic inducers and contribute to their therapeutic application.

\section{Material and methods}

Cell cultures and treatment. Human colon adenocarcinoma HT-29 cells (HTB 38, ATCC, Manassas, VA, USA) were cultured in McCoy's 5A medium (Sigma Aldrich, Prague, Czech Rep.) supplemented with gentamycin $(50 \mathrm{mg} / \mathrm{ml}$, Serva Electrophoresis GmbH, Heidelberg, Germany) and $10 \%$ fetal calf serum (FCS, PAN Biotech GmbH, Aidenbach, Germany). The normal human colon FHC cells (CRL-1831, ATCC) were cultured in a 1:1 mixture of Ham's F12 and Dulbecco's modified Eagle's medium (Sigma Aldrich) containing HEPES $(25 \mathrm{mM})$, cholera toxin $(10 \mathrm{ng} / \mathrm{ml}$, Calbiochem-Novabiochem Corp., La Jolla, CA, USA), insulin $(5 \mu \mathrm{g} / \mathrm{ml})$, transferrin $(5 \mu \mathrm{g} / \mathrm{ml})$ and hydrocortisone (100 ng/ml, all Sigma Aldrich) and 10\% FCS. Twenty-four hours after seeding, the cells were treated with TNF- $\alpha(15 \mathrm{ng} /$ $\mathrm{ml}$, Sigma Aldrich), anti-Fas antibody (CH-11, $200 \mathrm{ng} / \mathrm{ml}$, Immunotech, Marseilles, France) or TRAIL (100 ng/ml, kindly provided by Dr L. Andera, IMG Prague, Czech Rep.). The protein synthesis inhibitor cycloheximide (CHX, $5 \mu \mathrm{g} / \mathrm{ml}$, Sigma Aldrich) or the MEK1/2 inhibitor (ERK 1/2) U0126 (10 $\mu \mathrm{M}$, Cell Signaling Technology, Inc., Beverly, MA, USA) were applied simultaneously with TRAIL for 4 or $24 \mathrm{~h}$.

Floating cell quantification and viability assays. Floating and adherent cells were counted separately using a Coulter Counter (model ZM, Beckman Coulter, Inc., Fullerton, CA, USA) and the amount of floating cells was expressed as a percentage of the total cell number. Cell viability was determined by an eosin $(0.15 \%)$ dye exclusion assay.

Cell cycle analysis. Fixed cells were washed with PBS, lowmolecular-weight fragments of DNA were extracted from a citrate buffer $\left(\mathrm{Na}_{2} \mathrm{HPO}_{4}, \mathrm{C}_{6} \mathrm{H}_{3} \mathrm{O}_{7}, \mathrm{pH} 7.8\right)$, RNA was removed by ribonuclease A ( $5 \mathrm{Kunitz} \mathrm{U} / \mathrm{ml}$ ) and DNA was stained with propidium iodide (PI, $20 \mu \mathrm{g} / \mathrm{ml} \mathrm{PBS}$ ) for $30 \mathrm{~min}$ in the dark. Fluorescence was measured using a flow cytometer (FACSCalibur, Becton-Dickinson, San Jose, CA, USA) equipped with an argon ion laser at a $488 \mathrm{~nm}$ wavelength for excitation. A total of $2 \times 10^{4}$ cells was analysed in each sample. The ModFit 2.0 (Verity Software House, Topsham, CA, USA) and CellQuest (Becton-Dickinson) software were used to generate DNA content frequency histograms and quantify the amount of the cells in individual cell cycle phases including the $\mathrm{subG}_{0} / \mathrm{G}_{1}$ population.

Fluorescence microscopy. The cells were stained with a 4,6diamidino-2-phenyl-indol (DAPI, Fluka, Buchs, Switzerland) solution as previously described (14) and the percentage of apoptotic cells (with chromatin condensation and fragmentation) was determined as a percentage of apoptotic cells from a total number of 200 cells counted using a fluorescence microscope (Olympus IX-70).

Expression of the mitochondrial membrane APO2.7 protein. The cells $\left(1 \times 10^{6}\right)$ were washed in PBS and permeabilised by digitonin $(100 \mu \mathrm{g} / \mathrm{ml}$, Sigma Aldrich) in PBSF (2.5\% fetal calf serum and $0.1 \% \mathrm{NaN}_{3}$ in PBS) on ice for $20 \mathrm{~min}$ and then washed in PBS. The Apo2.7 protein was marked using antiApo2.7 antibody conjugated with phycoerythrin (Immunotech). The cells were incubated with $20 \mu \mathrm{l}$ of antibody and $80 \mu \mathrm{l}$ of PBSF at room temperature for $15 \mathrm{~min}$ in the dark. Fluorescence was measured using a flow cytometer (a total of $2 \times 10^{4}$ cells in each sample) and analysed for the percentage of APO2.7 positive cells using the CellQuest software.

Caspase activities. Caspase activities were measured by fluorimetry (Fluostar Galaxy, BMG Lab Technologies GmbH, Offenburg, Germany) using caspase-3 (Ac-DMQD-AMC, $50 \mu \mathrm{M}$, Alexis, Carlsbad, CA, USA) or caspase-9 (Ac-LEHDAMC, $50 \mu \mathrm{M}$, Alexis) substrates as previously described (15). Caspase-9 activity was inhibited by a specific caspase-9 inhibitor (Z-LEDH-FMK, Bio-Vision, Inc., New Minas, Canada).

Immunoblotting. The cells lysed in Laemmli sample buffer and diluted to an equal concentration were processed and subjected to SDS-PAGE as previously described (15). The membranes were then probed with anti-PARP (SC-7150, Santa Cruz Biotechnology, Santa Cruz, CA, USA), anti-Bid (SC-6538, Santa Cruz Biotechnology), anti-FLIP (AAP-440, StressGen Biotechnologies Corp., Victoria, BC, Canada), anti-DR5 (D3938, Sigma Aldrich) or anti-DcR2 (68861N, Pharmingen, BD Biosciences, San Jose, CA, USA) antibodies. The recognised proteins were detected using horseradish peroxidase-labelled rabbit (no. NA934, Amersham Biosciences, Buckinghamshire, UK) or mouse (no. NA931, Amersham Biosciences) anti-IgG secondary antibody and an enhanced chemiluminescence kit (ECL, Amersham Biosciences). An equal loading was verified using $B$-actin (A5441, Sigma-Aldrich) quantification.

Statistical analysis. The results of at least three independent experiments were expressed as the means \pm SEM. Statistical significance $(\mathrm{P}<0.05$ and $\mathrm{P}<0.01)$ was determined by oneway ANOVA followed by Tukey or LSD tests, or by a nonparametric Mann-Whitney U test.

\section{Results}

Parameters reflecting cell proliferation and death were detected in the HT-29 and FHC cells after $24 \mathrm{~h}$ of treatment with TNF- $\alpha$, anti-Fas or TRAIL. Moreover, the modulation of these parameters after a combined treatment of the cells with apoptotic inducers and the protein synthesis inhibitor cycloheximide (CHX) or MEK1/2 inhibitor U0126 was evaluated. The concentrations of the drugs used were selected on the basis of our previous experiments $(14,16,17)$ and doses were routinely used for this type of cells.

The effects of TNF- $\alpha$, anti-Fas and TRAIL on cell proliferation. In selected concentrations, none of the TNF-family apoptotic 
Table I. Quantification of cell death after $24 \mathrm{~h}$ of treatment of the HT-29 and FHC cells with TNF- $\alpha$ (TNF, $15 \mathrm{ng} / \mathrm{ml})$, anti-Fas $(\mathrm{CH} 11,200 \mathrm{ng} / \mathrm{ml})$, TRAIL $(100 \mathrm{ng} / \mathrm{ml})$ or their combinations with $\mathrm{CHX}(5 \mu \mathrm{g} / \mathrm{ml})$.

$\%$ of floating cells
$\%$ of cells in $\mathrm{subG}_{0}$ population
$\%$ of apoptotic cells (DAPI staining)

\begin{tabular}{lllllll}
\hline Treatment groups & HT-29 & FHC & HT-29 & FHC & HT-29 & FHC \\
Control & $10.02 \pm 5.42$ & $7.66 \pm 3.30$ & $2.54 \pm 1.17$ & $2.80 \pm 1.05$ & I.79 \pm 0.90 & $1.38 \pm 0.59$ \\
TNF & $12.41 \pm 6.49$ & $10.56 \pm 4.70$ & $5.12 \pm 3.82$ & $4.46 \pm 2.96$ & $2.33 \pm 0.90$ & $2.10 \pm 0.94$ \\
TNF+CHX & $27.53 \pm 4.56^{\text {a }}$ & $17.45 \pm 5.22^{\mathrm{a}}$ & $15.09 \pm 3.93^{\mathrm{a}}$ & $17.04 \pm 7.87^{\mathrm{b} \S}$ & $7.63 \pm 1.38^{\mathrm{b}}$ & $7.50 \pm 3.50^{\mathrm{b}}$ \\
CH11 & $21.82 \pm 8.27^{\mathrm{a}}$ & $12.29 \pm 4.90$ & $15.79 \pm 7.56^{\mathrm{b}}$ & $12.49 \pm 7.80^{\mathrm{a}}$ & $6.89 \pm 2.62^{\mathrm{b}}$ & $3.83 \pm 1.43^{\mathrm{a}}$ \\
CH11+CHX & $38.91 \pm 1.97^{\mathrm{b} \S}$ & $49.23 \pm 17.50^{\mathrm{b}}$ & $18.45 \pm 3.05^{\mathrm{a}}$ & $21.83 \pm 2.38^{\mathrm{b}}$ & $11.75 \pm 3.38^{\mathrm{b}}$ & $11.13 \pm 4.69^{\mathrm{b}}$ \\
TRAIL & $41.55 \pm 5.40^{\mathrm{b} \#}$ & $24.03 \pm 10.59^{\mathrm{b}}$ & $15.37 \pm 4.65^{\mathrm{b}}$ & $9.80 \pm 4.56^{\mathrm{b}}$ & $12.43 \pm 5.80^{\mathrm{b}}$ & $6.53 \pm 1.88^{\mathrm{b}}$ \\
TRAIL+CHX & $54.58 \pm 2.60^{\mathrm{b} \S}$ & $63.54 \pm 14.93^{\mathrm{b}}$ & $21.16 \pm 4.06^{\mathrm{a}}$ & $27.66 \pm 3.97^{\mathrm{b}}$ & $17.50 \pm 4.25^{\mathrm{b}}$ & $16.63 \pm 6.23^{\mathrm{b}}$ \\
\hline
\end{tabular}

The values arc means \pm SEM of at least three independent experiments; ${ }^{\text {P }}<0.05$ ( $\left.{ }^{b} \mathrm{P}<0.01\right)$ versus untreated control; ${ }^{\circledR} \mathrm{P}<0.05$ ( $\left.{ }^{\mathrm{g}} \mathrm{P}<0.01\right)$ versus $\mathrm{TNF}-\alpha$, anti-Fas or TRAIL alone treatment; ${ }^{~} \mathrm{P}<0.05$ between HT-29 and FHC cells.

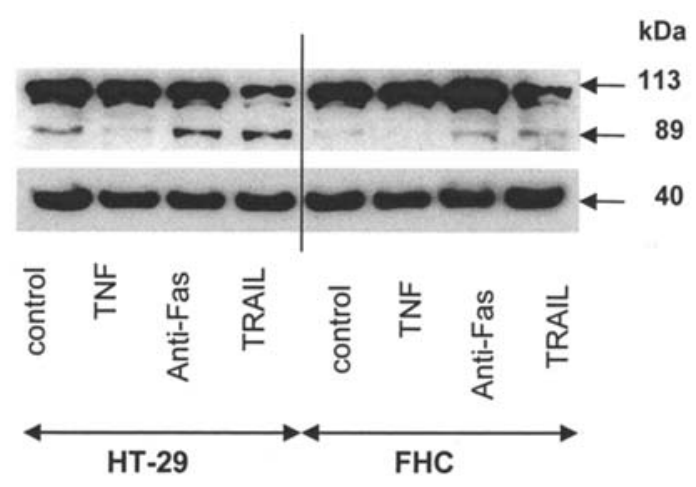

Figure 1. Cleavage of PARP and B-actin quantification in the HT-29 and FHC cells treated with TNF- $\alpha(15 \mathrm{ng} / \mathrm{ml})$, anti-Fas $(200 \mathrm{ng} / \mathrm{ml})$ or TRAIL $(100 \mathrm{ng} / \mathrm{ml})$ for $24 \mathrm{~h}$, detected by Western blotting. The results are representative of three independent experiments.

inducers caused significant changes in the total cell number and cycle parameters of HT-29 and FHC cells after $24 \mathrm{~h}$ of treatment (data not shown).

The effects of TNF- $\alpha$, anti-Fas, and TRAIL on cell death. As is apparent from Table I, neither HT-29 nor FHC cells responded to TNF- $\alpha$ in the used concentration $(15 \mathrm{ng} / \mathrm{ml})$ and incubation time $(24 \mathrm{~h})$. An increase of parameters reflecting the cell death (cell detachment, $\operatorname{subG}_{0} / \mathrm{G}_{1}$ population and cells with apoptotic nuclear morphology) was observed after anti-Fas treatment with a slightly stronger response of the HT-29 cells. The two cell lines studied differed significantly in their susceptibility to TRAIL. The values of the three abovementioned parameters detected were about two-fold higher in the HT-29 than in FHC cells. The two cell types were markedly sensitised to all apoptotic inducers by the addition of CHX (Table I). The differences in the apoptotic effects of TNF- $\alpha$, anti-Fas and TRAIL were further confirmed by the detection of PARP cleavage (Fig 1A). PARP was not cleaved after TNF- $\alpha$ treatment in the HT-29 and FHC cells. After treatment of cells with anti-Fas and particularly TRAIL, a more intensive PARP cleavage in the HT-29 than in FHC cells was detected.

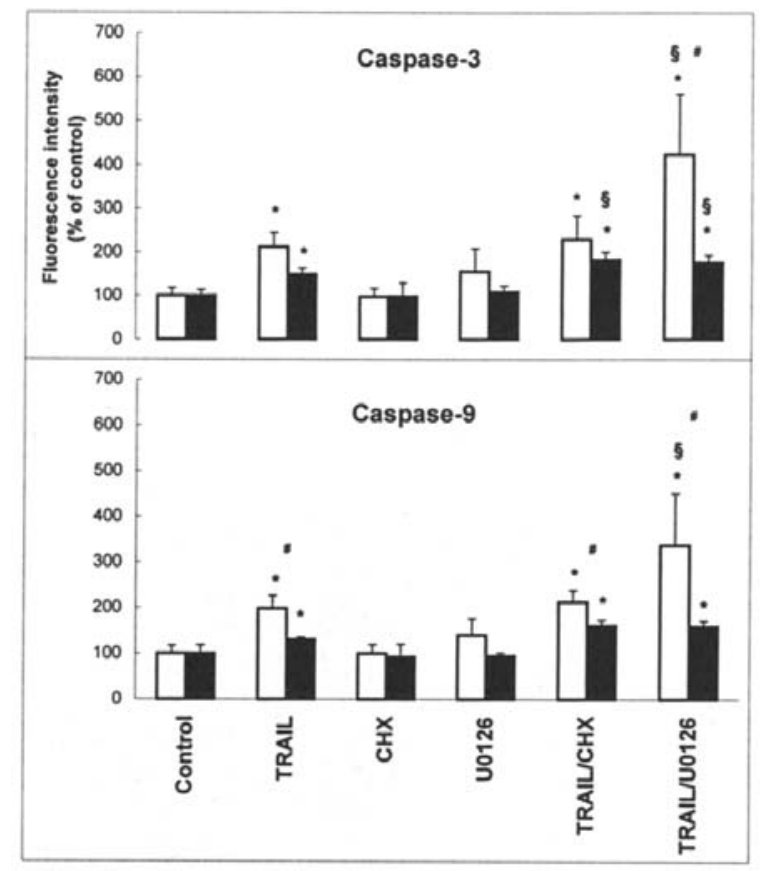

Figure 2. Caspase-3 and -9 activities (\% of control) after treatment (4 h) of HT-29 (white column) and FHC cells (black column) with TRAIL (100 ng/ $\mathrm{ml}), \mathrm{CHX}(5 \mu \mathrm{g} / \mathrm{ml}), \mathrm{U} 0126(10 \mu \mathrm{M})$, or their combinations; $\mathrm{P}<0.05$ : *, versus untreated control; §, versus TRAIL alone; \#, between HT-29 and FHC cells.

Differences in the HT-29 and FHC cell response to TRAIL. Besides the parameters evaluated above, our attention focused on other plausible determinants of the different sensitivity of HT-29 and FHC cells to TRAIL effects.

Caspase activities. TRAIL induced an increase in caspase activities in the two cell lines. Higher activities of caspases-9, and -3 after $4 \mathrm{~h}$ of TRAIL treatment were detected in HT-29 compared to the FHC cells (Fig. 2). These differences between the two cell lines were further significantly enhanced by cotreatment of the cells with TRAIL and U0126. A combined treatment of the cells with TRAIL and CHX did not significantly increase the caspase- 3 and -9 activities in comparison with TRAIL alone in the time interval studied. 


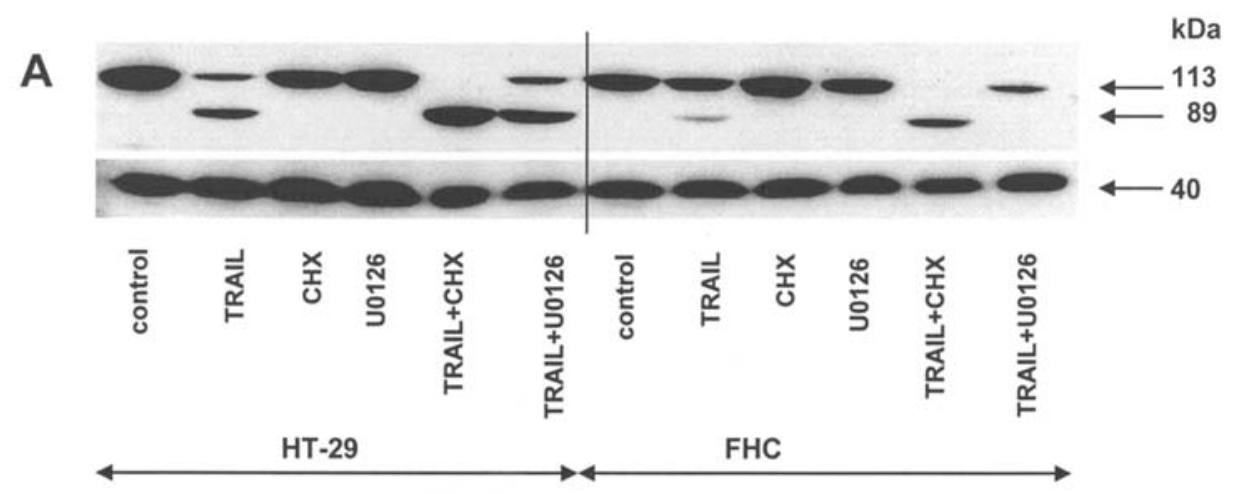

B

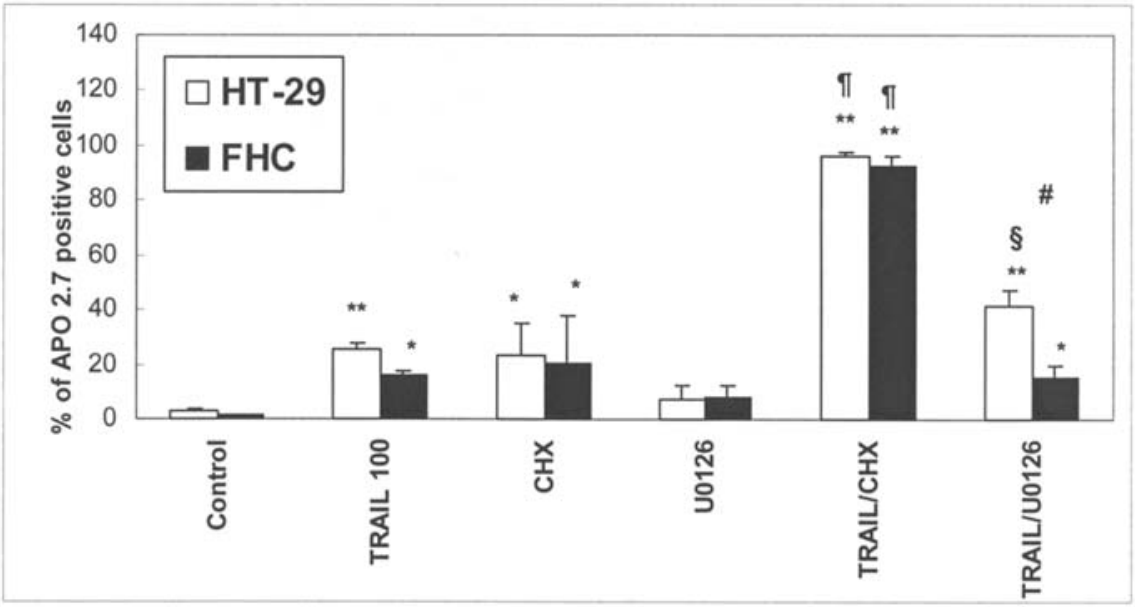

Figure 3. (A) Cleavage of PARP and B-actin quantification in HT-29 and FHC cells treated with TRAIL (100 ng/ml), CHX (5 $\mu \mathrm{g} / \mathrm{ml})$, U0126 (10 $\mu \mathrm{M})$ or their combinations for $24 \mathrm{~h}$, detected by Western blotting. The results are representative of three independent experiments. (B) Expression of mitochodrial APO2.7 protein (\% of positive cells) after $24 \mathrm{~h}$ treatment of HT-29 and FHC cells with TRAIL (100 ng/ml), CHX (5 $\mu \mathrm{g} / \mathrm{ml})$, U0126 (10 $\mu \mathrm{M})$ or their combination; $* \mathrm{P}<0.05(* * \mathrm{P}<0.01)$, versus untreated control; $\S, \mathrm{P}<0.05$ (I, $\mathrm{P}<0.01)$ versus TRAIL alone; \#, between HT-29 and FHC cells.

PARP cleavage. The results of PARP cleavage (Fig. 3A) showed a more intensive effect of TRAIL in the HT-29 than in FHC cells. Further potentiation of PARP cleavage by CHX as well as by U0126 was detected in the cell lines. However, a combined treatment with TRAIL and U0126 resulted in a different cleavage pattern in the FHC cells compared to the HT-29 cells (lack of $89 \mathrm{kDa}$ cleavage product).

Expression of the APO2.7 mitochondrial protein. The APO2.7 antigen is specifically expressed on the mitochondrial membrane of cells undergoing apoptosis. After $24 \mathrm{~h}$ of TRAIL treatment, the number of cells with APO2.7 positivity confirmed a higher apoptotic effect of TRAIL on the HT-29 than on FHC cells. CHX strongly potentiated this effect in the two cell lines, shifting positivity to $\sim 95 \%$ of the cells. Moreover, in the HT-29 cells, but not in the FHC cells, the percentage of APO2.7 cells was significantly increased by co-treatment with U0126 (Fig. 3B).

Expression of DR5, DcR2 and FLIP. No significant differences in the expression of DR5 protein detected by Western blotting between the HT-29 and FHC cells were observed. As shown in Fig. 4A, co-treatment of the cells with TRAIL and CHX resulted in its loss in both cell types.

Compared to the HT-29 cells, FHC cells presented a higher expression of the DcR2 protein, which was slightly decreased by a combined treatment with TRAIL and CHX (Fig. 4 B).
The expression of FLIP was decreased after TRAIL treatment in the two cell lines. This effect was significantly potentiated by CHX. Compared to TRAIL alone, a slight but not statistically significant additional decrease of FLIP expression was observed after co-treatment with TRAIL and U0126 in the two cell lines (Fig. 4C).

Expression of Bcl-2 family proteins. The expression of $\mathrm{Bcl}-2$ family proteins was examined $24 \mathrm{~h}$ after treatment with TRAIL and its combination with CHX or U0126. The HT-29 cells expressed no Bcl-2 protein. While no changes of the Bax and Bak expression were observed after any type of treatment (data not shown), a significant cleavage of Bid was detected. In HT-29 cells, the Bid protein was more intensively cleaved after $24 \mathrm{~h}$ of TRAIL treatment in comparison with FHC cells. A strong potentiation of this effect (almost complete cleavage) by co-treatment with $\mathrm{CHX}$ was detected in the two cell lines (Fig. 4D).

\section{Discussion}

We showed that the triggering of the TNF family receptors can induce a different degree of response in cancer HT-29 and non-cancer FHC human colon cells. While the two cell types did not respond to TNF- $\alpha$ in the concentration used, they showed a recognizable response to anti-Fas antibody and a markedly different response to TRAIL-mediated apoptosis. 

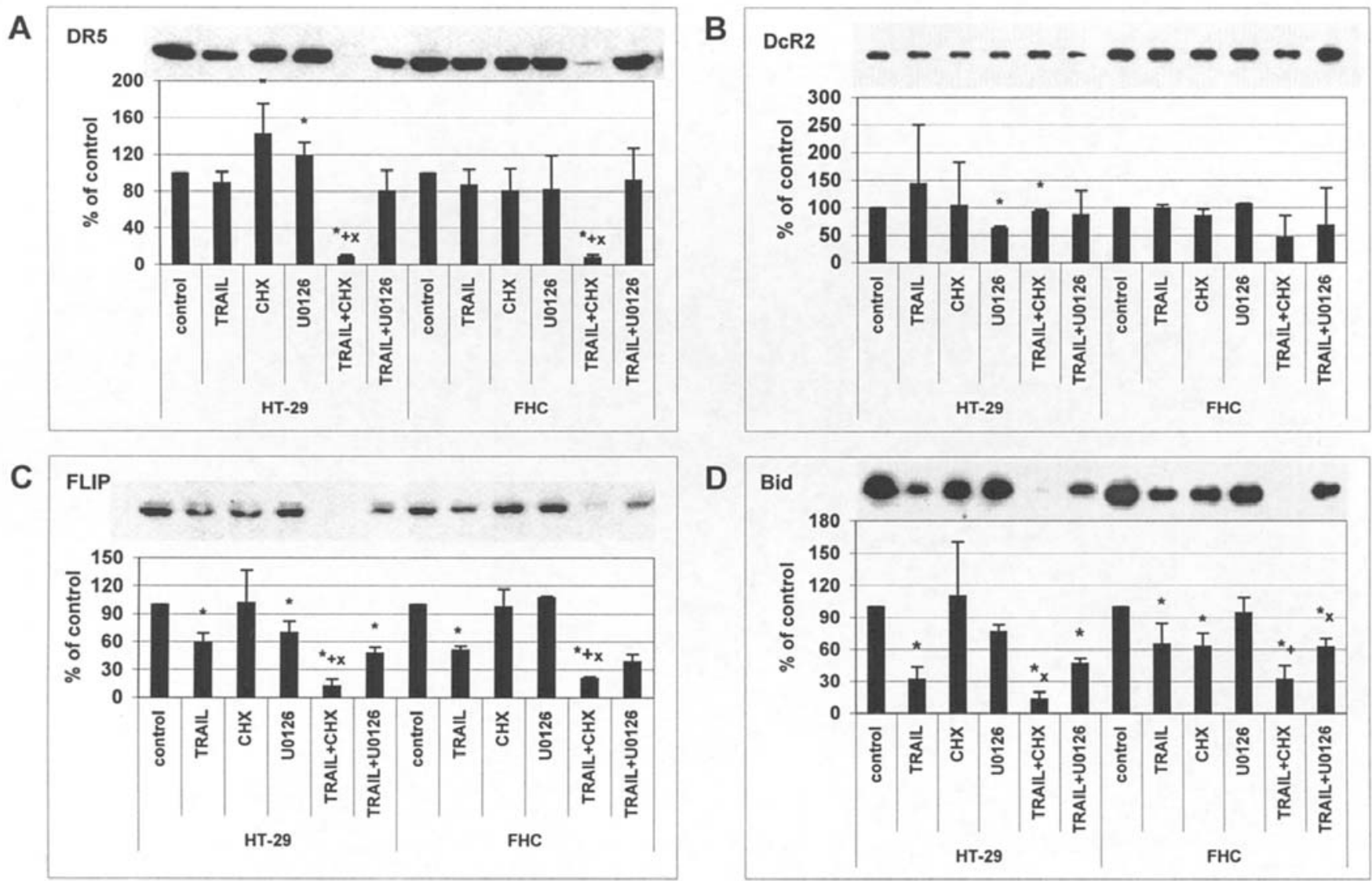

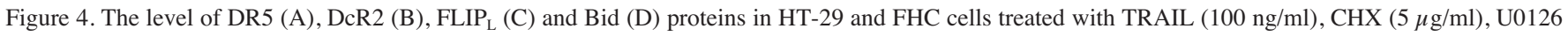
$(10 \mu \mathrm{M})$ or their combinations for $24 \mathrm{~h}$. Representative Western blots and the means \pm SEM of optical densities (related to $B$-actin content) are presented; $\mathrm{P}<0.05$ : *, versus untreated control; +, versus TRAIL, $\mathrm{x}$, versus CHX.

Our results showed a different sensitivity of normal and cancer colon cells to TNF family molecules which implies that a synthesis of specific proteins involved in intracellular signalling pathways determines the cell response.

The relatively slow nature of death receptor-induced death in HT-29 cells has been reported (18). In our previous experiments, TNF- $\alpha$ initially induced dose-dependent growth arrest and its cytotoxicity was enhanced only by the cultivation of HT-29 cells for longer time intervals (16), even though the activation of caspase- 3 and PARP cleavage was detected earlier (17). In the experiments presented here, no effects on proliferation and cell death were detected either in the HT-29 or FHC cells after $24 \mathrm{~h}$ of treatment with TNF- $\alpha$, which elicited acute apoptotic effects only when administered along with $\mathrm{CHX}$.

HT-29 cells seem to be slightly more sensitive to the effects of anti-Fas antibody than FHC cells. As with TNF- $\alpha$, cell sensitivity can be increased by CHX. Colon carcinoma cell lines usually show relative resistance to CD95-inducible cell death and a malignant transformation of colon epithelium is often accompanied by abnormally low levels of CD95 protein (19). However, we detected only a low expression of the CD95 receptor in the normal and cancer colon cell lines (data not shown). It is supposed that the apoptotic responsiveness to CD95 crosslinking may be more complex and remains to be further elucidated (20).
As expected, HT-29 cells presented a higher sensitivity to TRAIL than FHC cells, and the sensitivity of the two cell types was increased by CHX. Molecular determinants of response to TRAIL on various levels of the signalling pathway are suggested and they vary among different cell types (21). At the receptor level, a high expression of DR4 and DR5 was reported in various types of colorectal neoplastic disorders (22). Cells may become resistant through regulation of the DR cell surface transport and/or their re-localisation in the plasma membrane $(23,24)$. Our results showed that there are no significant differences in the level of DR5 between HT-29 and FHC cells. Notably, DR5 was lost after co-treatment with TRAIL and CHX, which proves the role of a new protein synthesis in the regulation of the level of this receptor. Furthermore, the decoy receptors were shown to be involved in the regulation of cell sensitivity/resistance to TRAIL effects in certain cell lines. In our experiments, the increased level of DcR2 in the FHC cells as compared to the HT-29 cells was demonstrated, suggesting that it could contribute to a higher resistance of normal colon cells to TRAIL. The amount of DcR2 in FHC cells was also suppressed by a combined treatment with TRAIL and CHX.

The FLICE-like inhibitory protein (cFLIP) may produce resistance at the level of the death-receptors by the inhibition of caspase- 8 activation. An increased expression of $\mathrm{cFLIP}_{\mathrm{L}}$ 
was shown to be a frequent event in colon adenocarcinomas (25). Moreover, its specific siRNA-mediated down-regulation has been found to sensitize colon cancer cells to TRAILinduced apoptosis $(26,27)$. In our experiments, HT-29 cells also expressed a relatively high level of $\mathrm{FLIP}_{\mathrm{L}}$. Notably, we found no significant difference in the $\mathrm{cFLIP}_{\mathrm{L}}$ level between the cancer HT-29 and normal FHC colon cell lines. However, a decrease of its expression after TRAIL treatment and its complete loss caused by co-treatment with $\mathrm{CHX}$ was observed in the two cell lines. This is in agreement with the fact that regulatory proteins with a short half-life (such as cFLIP) belong to the important targets of CHX effects, thus playing a key role in the modulation of cell sensitivity to TRAIL (28). We suggest that modulation of the $\mathrm{CFLIP}_{\mathrm{L}}$ level may be an important determinant of the sensitivity to TRAIL effects in cancer and normal colon cell lines.

Both HT-29 and FHC cells seem to be type II cells (intrinsic apoptotic pathway) because the Bid-dependent mitochondrial amplification loop was functional. The BH3only protein Bid provides a link between the receptormediated and mitochondrial pathway. In our experiments, TRAIL-induced Bid cleavage was accompanied by an increased mitochondrial APO2.7 protein expression, a decrease of MMP (not shown) and the activation of caspase-9. Moreover, the apoptosis induced by TRAIL was partially reversed by caspase- 9 inhibition (not shown). Described responses were significantly weaker in FHC cells compared to HT-29 cells and were potentiated by $\mathrm{CHX}$ in the two cell lines. These results correspond with the suggestion that in a cell line where DISC-generated initiator caspase activity is insufficient to fully activate enough caspase-3 to kill the cell, the cleavage of Bid followed by further events at the level of mitochondria (involving interplay between the $\mathrm{Bcl}-2$ protein family members) is necessary for full caspase activation and apoptosis (6). A truncated Bid interacts with the pro-apoptotic proteins Bax and Bak, resulting in the release of pro-apoptotic factors such as cytochrome $\mathrm{c}$ from mitochondria. In our experiments, TRAIL induced no significant changes in the expression of Bax nor Bak in neither the HT-29 nor FHC cells (not shown).

Previously, we showed that the specific inhibition of the ERK1/2 pathway (U0126) sensitized the HT-29 cells, but not the SW620 cells to TRAIL-induced apoptosis (29). These cells differed significantly in their response to the apoptotic effects of TRAIL (100 ng/ml), with the SW620 cells being resistant. In the present study, we examined the role of the ERK1/2 pathway in the regulation of TRAIL-induced apoptosis found in normal colon FHC cells. As our previous (29) and present results showed a significant U0126-mediated potentiation of the intrinsic apoptotic pathway induced by TRAIL in the HT-29 cells, we compared the response between HT-29 and FHC cells especially with regard to the involvement of mitochondria. The ERK-mediated protection from TRAILinduced apoptosis via the inhibition of the apoptotic changes at the level of mitochondria has also been reported in other cancer cell lines (30). We showed that in contrast to HT-29 cells, U0126 was not sufficient for a significant potentiation of the TRAIL-induced apoptotic pathway at the level of these organelles in FHC cells, as demonstrated by caspase- 9 activity and Apo2.7 protein expression. Moreover, the overall rate of apoptosis (apoptotic nuclear morphology, caspase-3 activity and PARP cleavage) after a combined TRAIL and U0126 treatment was also significantly lower in the FHC cells as compared to the HT-29 cells. Thus, it seems that inhibition of the MEK/ERK pathway is more efficient in the potentiation of TRAIL-induced apoptotis in HT-29 than in FHC cells.

To summarize, neither the HT-29 cancer nor the FHC non-cancer cells responded to TNF- $\alpha$ in the concentration used, while the anti-Fas antibody and especially TRAIL induced a more apparent response in the HT-29 cells. While the two cell lines were markedly sensitized to all three TNF family members by CHX, a different degree of response was obtained when inhibition of the MEK/ERK pathway was achieved. U0126 was not effective in the modulation of TNF- $\alpha$ - or anti-Fas-induced apoptosis neither in the HT-29, nor in the FHC cells (not shown). TRAIL-induced apoptosis was significantly enhanced by a U0126 co-treatment in the HT-29 cells, but not in the FHC cells. We compared the cell apoptotic response with regard to the changes at the receptor level (DR5, DcR2 and FLIP) and at the level of mitochondria (Bid cleavage, Apo2.7 protein expression and caspase-9 activation). The most significant differences between the HT-29 and FHC cells co-treated with TRAIL and U0126 were demonstrated with regard to the involvement of the mitochondrial apoptotic pathway, suggesting its importance in the regulation of cell sensitivity to the TRAIL-induced apoptosis.

\section{Acknowledgements}

This work was supported by the Grant Agency of the Czech Republic, grant No. 524/07/1178, the Academy of Sciences of the Czech Republic, grant No. KJB500040508 and the Research Plan AVOZ50040507.

\section{References}

1. Lifshitz S, Lamprecht SA, Benharroch D, Prinsloo I, Polak-Charcon S and Schwartz B: Apoptosis (programmed cell death) in colonic cells: from normal to transformed stage. Cancer Lett 163: 229-238, 2001.

2. Strater J and Moller P: Expression and function of death receptors and their natural ligands in the intestine. Ann NY Acad Sci 915: 162-170, 2000.

3. Manos EJ and Jones DA: Assessment of tumor necrosis factor receptor and Fas signaling pathways by transcriptional profiling. Cancer Res 61: 433-438, 2001.

4. MacFarlane M: TRAIL-induced signalling and apoptosis. Toxicol Lett 139: 89-97, 2003.

5. Ozoren N and El-Deiry WS: Defining characteristics of Types I and II apoptotic cells in response to TRAIL. Neoplasia 4: 551-557, 2002.

6. Sprick MR and Walczak H: The interplay between the Bcl-2 family and death receptor-mediated apoptosis. Biochim Biophys Acta 1644: 125-132, 2004.

7. Jaattela M: Biologic activities and mechanisms of action of TNF-alpha/Cachektin. Biol Dis 64: 724-742, 1991.

8. Krammer PH, Galle PR, Moller P and Debatin KM: CD95 (APO-1/Fas)-mediated apoptosis in normal and malignant liver, colon, and hematopoietic cells. Adv Cancer Res 75: 251-273, 1998.

9. Velthuis JH, Rouschop KM, De Bont HJ, Mulder GJ and Nagelkerke JF: Distinct intracellular signaling in tumor necrosis factor-related apoptosis-inducing ligand- and CD95 ligandmediated apoptosis. J Biol Chem 277: 24631-24637, 2002.

10. Fiorucci G, Vannucchi S, Chiantore MV, Percario ZA, Affabris E and Romeo G: TNF-related apoptosis-inducing ligand (TRAIL) as a pro-apoptotic signal transducer with cancer therapeutic potential. Curr Pharm Des 11: 933-944, 2005. 
11. Hague A, Hicks DJ, Hasan F, Smartt H, Cohen GM, Paraskeva C and MacFarlane M: Increased sensitivity to TRAIL-induced apoptosis occurs during the adenoma to carcinoma transition of colorectal carcinogenesis. Br J Cancer 92: 736-742, 2005.

12. Van Geelen CM, de Vries EG and de Jong S: Lessons from TRAIL-resistance mechanisms in colorectal cancer cells: paving the road to patient-tailored therapy. Drug Resist Updat 7: 345-358, 2004.

13. Kim K, Fisher MJ, Xu SQ and el-Deiry WS: Molecular determinants of response to TRAIL in killing of normal and cancer cells. Clin Cancer Res 6: 335-346, 2000.

14. Hofmanova J, Vaculova A and Kozubik A: Polyunsaturated fatty acids sensitize human colon adenocarcinoma HT-29 cells to death receptor-mediated apoptosis. Cancer Lett 218: 33-41, 2005.

15. Vaculova A, Hofmanova J, Soucek K, Andera L and Kozubik A: Ethanol acts as a potent agent sensitizing colon cancer cells to the TRAIL-induced apoptosis. FEBS Lett 577: 309-313, 2004.

16. Kovarikova M, Pachernik J, Hofmanova J, Zadak Z and Kozubik A: TNF-alpha modulates the differentiation induced by butyrate in the HT-29 human colon adenocarcinoma cell line. Eur J Cancer 36: 1844-1852, 2000.

17. Vaculova A, Hofmanova J, Soucek K, Kovarikova M and Kozubik A: Tumor necrosis factor-alpha induces apoptosis associated with poly(ADP-ribose) polymerase cleavage in HT-29 colon cancer cells. Anticancer Res 22: 1635-1639, 2002.

18. Wilson CA and Browning JL: Death of HT29 adenocarcinoma cells induced by TNF family receptor activation is caspaseindependent and displays features of both apoptosis and necrosis. Cell Death Differ 9: 1321-1333, 2002.

19. von Reyher U, Strater J, Kittstein W, Gschwendt M, Krammer PH and Moller P: Colon carcinoma cells use different mechanisms to escape CD95-mediated apoptosis. Cancer Res 58: 526-534, 1998.

20. Strater J and Moller P: CD95 (Fas/APO-1)/CD95L in the gastrointestinal tract: fictions and facts. Virchows Arch 442: 218-225, 2003.

21. Zhang XD, Nguyen T, Thomas WD, Sanders JE and Hersey P: Mechanisms of resistance of normal cells to TRAIL induced apoptosis vary between different cell types. FEBS Lett 482: 193-199, 2000.
22. Koornstra JJ, Jalving M, Rijcken FE, et al: Expression of tumour necrosis factor-related apoptosis-inducing ligand death receptors in sporadic and hereditary colorectal tumours: potential targets for apoptosis induction. Eur J Cancer 41: $1195-1202,2005$.

23. Jin Z, McDonald ER 3rd, Dicker DT and El-Deiry WS: Deficient tumor necrosis factor-related apoptosis-inducing ligand (TRAIL) death receptor transport to the cell surface in human colon cancer cells selected for resistance to TRAILinduced apoptosis. J Biol Chem 279: 35829-35839, 2004.

24. Muppidi JR, Tschopp J and Siegel RM: Life and death decisions: secondary complexes and lipid rafts in TNF receptor family signal transduction. Immunity 21: 461-465, 2004.

25. Ryu BK, Lee MG, Chi SG, Kim YW and Park JH: Increased expression of cFLIP(L) in colonic adenocarcinoma. J Pathol 194: 15-19, 2001

26. Galligan L, Longley DB, McEwan M, Wilson TR, McLaughlin K and Johnston PG: Chemotherapy and TRAIL-mediated colon cancer cell death: the roles of p53, TRAIL receptors, and cFLIP. Mol Cancer Ther 4: 2026-2036, 2005.

27. Lippa MS, Strockbine LD, Le TT, Branstetter DG, Strathdee CA and Holland PM: Expression of anti-apoptotic factors modulates Apo2L/TRAIL resistance in colon carcinoma cells. Apoptosis (In press).

28. van Geelen CM, de Vries EG, Le TK, van Weeghel RP and de Jong S: Differential modulation of the TRAIL receptors and the CD95 receptor in colon carcinoma cell lines. Br J Cancer 89: 363-373, 2003.

29. Vaculova A, Hofmanova J, Soucek K and Kozubik A: Different modulation of TRAIL-induced apoptosis by inhibition of prosurvival pathways in TRAIL-sensitive and TRAIL-resistant colon cancer cells. FEBS Lett 580: 6565-6569, 2006.

30. Zhang XD, Borrow JM, Zhang XY, Nguyen T and Hersey P: Activation of ERK1/2 protects melanoma cells from TRAILinduced apoptosis by inhibiting Smac/DIABLO release from mitochondria. Oncogene 22: 2869-2881, 2003. 